\title{
DE LA CIUDAD LETRADA A LAS VOCES IMPRESAS. UN RECORRIDO CONJETURAL
}

\author{
Hernán Pas \\ Instituto de Humanidades y Ciencias Sociales, IdHICS \\ Universidad Nacional de La Plata \\ Consejo Nacional de Investigaciones Científicas y Técnicas, CONICET \\ Argentina \\ hpas@fahce.unlp.edu.ar | hernan_pas@yahoo.com \\ ORCID: 0000-0003-4365-7662
}

Fecha de recepción: 28/06/202I | Fecha de aceptación: 08/07/2021

Resumen: Se despliega un panorama de los avances sobre el siglo XIX producidos en la crítica de las últimas décadas desde la impronta inicial del legado de Ángel Rama hasta el llamado giro material. Se describe la relevancia que adquirieron las investigaciones sobre el formato periódico en los estudios sobre la producción, circulación y recepción literaria en ese siglo y se reseñan las contribuciones publicadas en la revista Anclajes como correlato de perspectivas más amplias sobre la edición, la literatura, la lectura.

Palabras clave: siglo XIX; periódico; historia de la edición; literatura latinoamericana; crítica literaria.

\section{From the letterate city to the printed voices. A conjectural tour}

Abstract:A panorama of the advances on the 19th century produced in the criticism of the last decades is displayed from the initial imprint of Angel Rama's legacy to the so-called material turn. The relevance that research on the periodical format acquired in studies on literary production, circulation and reception in that century is described and the contributions published in Anclajes are reviewed as a correlate of broader perspectives on publishing, literature, and reading.

Keywords: XIX century; Newspaper; publishing history; Latin American literature; literary criticism.

\section{Da cidade letrada às vozes impressas. Um tour conjectural}

Resumo: Da impressão inicial do legado de Ángel Rama à chamada virada material, desdobra-se um panorama dos avanços do século XIX produzidos na crítica das últimas décadas. Descreve-se a relevância que a pesquisa sobre o formato do periódico adquiriu nos estudos sobre produção, circulação e recepção literária naquele século e as contri- 
buições publicadas na revista Anclajes são revisadas como um correlato de perspectivas mais amplas sobre publicação, literatura e literatura.

Palavras chave: século XIX; Jornal; história da publicação; Literatura latino-americana; Crítica literária.

a aparición del primer número de Anclajes (1997) coincidió, casualmente, con la publicación del volumen que el Instituto Internacional de Literatura Iberoamericana de la Universidad de Pittsburgh dedicó a una figura por demás señera de la crítica latinoamericana. En efecto, ese mismo año conocimos el compendio Ángel Rama y los estudios latinoamericanos, el cual, integrando la serie Críticas del IILI (edición a cargo de Mabel Moraña), se proponía como un balance, una especie de summa crítica del legado ramiano, a partir de la revisión y discusión de su producción ensayística e intelectual, en particular del impacto que produjo la lenta y póstuma recepción de La ciudad letrada ${ }^{1}$.

Si bien este no es lugar para describir dicho balance, pueden resumirse, grosso modo, dos de las principales líneas - no siempre antagónicas- de su legado como punto de partida para una reflexión sobre los cambios producidos en los estudios del siglo XIX durante los ańos de existencia de la revista: por un lado, el diseño de variables transcontinentales como herramienta de análisis para pensar los procesos de producción, circulación y recepción literaria, evitando los tradicionales enfoques nacionalistas de la crítica (y en particular, de la crítica dedicada a la formación del campo o del canon); por otro lado, concomitantemente, la figuración del sujeto letrado como detentador y reproductor del poder - una figuración históricamente casi imperturbable- que colocaba a la escritura (y a la literatura) en el lugar de la culpa, el control y el disciplinamiento, al mismo tiempo que dejaba fuera otras expresiones (letradas e iletradas) exógenas al canon -la escritura era vector y metáfora, al mismo tiempo, de la "ciudad amurallada"-.

El libro de Rama respondía a aquellas lecturas genealógicas (la presencia de Foucault, aunque evidente, no resulta demasiado operativa en relación con este aspecto) y totalizadoras, que postulaban una narrativa historiográfica desagregada de las historias nacionales. Como Orientalism (1978), de Edward Said, con el que tiene más de un punto en común, o como Imagined Communities (1983), del historiador anglo-irlandés Benedict Anderson, La ciudad letrada también

1 La totalidad de los dieciséis trabajos que integran el volumen sobrevuelan La ciudad letrada y cinco de ellos lo tienen como objeto central de sus argumentos. Casi una década después -señal de su permanencia estimulante- la revista de historia intelectual Prismas, bajo el título "La ciudad letrada: hacia una historia de las élites intelectuales en América Latina”, dedicó un dossier a revisar y discutir ese libro fundamental (Prismas, Año 10, $\mathrm{N}^{\circ} 10,2006$, pp. 157-212). 
era un modo de leer procesos técnicos y simbólicos de largo alcance, comunes y transnacionales ${ }^{2}$.

Esa misma pretensión, como dijimos, repercutía en la construcción de categorías transhistóricas y/o monolíticas (sujeto letrado / cultura letrada / ciudad escrituraria), refractarias a matices o inflexiones sociológicas, culturales, o económicas. En una de las tempranas lecturas de La ciudad letrada, la crítica colonial Rolena Adorno, si bien reconocía el potencial de su conjetura simbólica (la escritura como fundadora de un orden) no dejaba de observar sin embargo que durante la colonia existieron "voces que vivían fuera de la ciudad amurallada" (5) y que debían, y podían, por tanto, ser registradas.

Julio Ramos, por su parte, en una revisión fundamental de los procesos de modernización literaria en América Latina sobre la que más adelante volveremos, señaló asimismo el carácter ahistórico del sujeto letrado ramiano, el cual no registraba los cambios ocurridos, sobre todo hacia el final de la centuria, en el régimen discursivo legitimador del escritor moderno.

En términos generales, en el ensayo de Rama el legado colonial se leía entonces como una constante, capaz de atravesar géneros y épocas. Una lectura así se convertía, inevitablemente, en una crítica ideológica, necesariamente desmitificadora, como la que venían proponiendo las agendas de los Cultural Studies. Había una delgada línea, sin embargo, entre la desmitificación y la condena. María Teresa Gramuglio, en un debate publicado en Punto de vista en el que no se hablaba necesariamente del siglo XIX, resumía la situación de este modo: "uno de los cambios más polémicos que han ocurrido en el campo de la crítica literaria contemporánea es el que va de una concepción de la literatura como práctica potencialmente crítica y liberadora, a una crítica de la literatura como institución de control." (4).

Aun a riesgo del reduccionismo alertado por Gramuglio, el acotado auge de los Estudios Culturales, las teorías coloniales o los diferentes subalternismos produjeron una apertura textual en el campo de los estudios decimonónicos, posibilitando la emergencia de interrelaciones disciplinares y nuevo objetos de estudio como la moda, los estudios de género, las sociabilidades, la glotopolítica, la cultura visual (el nuevo comparatismo, que merecería un capítulo aparte, también produjo cambios sustanciales en los modos de revisar las tradicionales relaciones entre centro (core)/periferia, copia/modelo; valga solamente citar aquí como ejemplo la imposición de los atlas, los sistemas, las redes, los mapas) ${ }^{3}$. La mirada facetada se impuso a la mirada totalizadora. Pero la fragmentación no olvidó, sino que fortaleció la mirada ramiana transfronteriza. Las historias

2 Su antecedente más elocuente en el campo historiográfico, La ciudad y las ideas, de José Luis Romero, también ensayaba una interpretación desafiante de los límites nacionales.

3 Para una aproximación al problema del nuevo comparatismo y la literatura latinoamericana, ver: Sánchez Prado, Ignacio M. (ed.). América Latina en la "literatura mundial", Pittsburgh, Instituto Internacional de Literatura Iberoamericana, Universidad de Pittsburgh, Biblioteca de América, 2006. 
nacionales de la literatura comenzaron a volverse críticas de sus propios presupuestos historiográficos, y a tender puentes o iluminar espacios compartidos, o a pensarse en términos contingentes, singulares, heteróclitos ${ }^{4}$.

A poco de andar, Anclajes se mostró como una revista receptiva de esos cambios, y promovió, tanto en su sección de reseñas como en su cuerpo central de artículos, el debate y la circulación de los nuevos enfoques. Algunos trabajos, por ejemplo, como el de María Pía Bruno sobre la Cuba de Domingo del Monte (2009, vol. 13, núm. 13), el de Hebe Beatriz Molina sobre las poco visitadas escritoras argentinas Margarita Rufina Ochagavía y M. Sasor (2011, vol. 15, núm. 2), o el de Virginia Forace sobre las Memorias curiosas de Juan Manuel Beruti (2015, vol. 19, núm. 1), muestran una inclinación por indagar en los bordes del canon.

A partir del intercambio epistolar entre el joven poeta José Jacinto Milanés y Domingo del Monte, Bruno logra auscultar el debate de un programa literario cubano en ciernes, en el cual se vislumbran las características propedéuticas de una literatura para el pueblo, pero también la subjetividad del hombre de letras, en este caso un poeta, como preludios lejanos de una (¿̨utura?) autofiguración literaria.

La apuesta de Virginia Forace es leer las Memorias curiosas de Juan Manuel Beruti evitando su craso sentido documental. Las llamadas Memorias, cuya crónica se extiende entre 1717 y 1855 , fueron iniciadas al parecer anónimamente, y Beruti habría decidido, siendo joven, continuarlas. Si de por sí la confección de ese testimonio resulta novelesca, Forace agudiza el aparato crítico (de Paul Ricoeur a Philippe Lejeune, pasando por José Luis Romero y Adolfo Prieto) para extraer de él no sólo la crónica de los hechos (cuyo estilo virará definitivamente con las invasiones inglesas) sino también, más relevante, el modo en que esa experiencia es convertida, finalmente, en relato.

La recuperación de dos escritoras argentinas "olvidadas", Margarita Rufina Ochagavía y Mercedes Rosas de Rivera, es decir la inspección de los márgenes del canon, le permite a Molina profundizar el debate (abierto por Graciela Batticuore a nivel local) respecto de las mediaciones por las cuales las mujeres pudieron o no dedicarse a la escritura en tanto que novelistas.

Esta mínima reseña procura exponer, sucintamente, no una tendencia ni una metodología sino un aspecto ostensible en algunos enfoques de los últimos ańos: la antańo omnipresente política cede -sin desaparecer del todo, desde ya- ante las persuasiones del detalle. El corrimiento de la política para que en su lugar

4 Como sabemos, con el pasaje al nuevo milenio se llevó a cabo en la Argentina la empresa editorial más importante de los últimos tiempos: entre 1999 y 2018 se publicaron los 12 volúmenes de la Historia crítica de la literatura argentina (Buenos Aires, Emecé), dirigida por Noé Jitrik. Por su parte, bajo la coordinación general de Grínor Rojo y Carol Arcos, en 2017 comenzó a publicarse en Chile una (también) Historia crítica de la literatura chilena (Santiago, LOM), proyectada en 5 volúmenes (de los cuales hasta ahora han aparecido 2: el volumen I, La era colonial, coordinado por Stefanie Massmann, y el volumen II, La era republicana. Independencia y formación del Estado nacional, a cargo de Bernardo Subercaseaux). 
aparezca lo otro, la literatura 5 . Eso, por un lado. Porque, por el otro, no sería difícil hallar un continente común, no explícitamente asumido, que recorre todos los trabajos: las producciones novelescas de M. Sasor y M. R. Ochagavía, como ha demostrado Molina también en trabajos previos, dialogan con las novelitas, crónicas y folletines que se publican en la prensa; las Memorias de Beruti lindan por momentos (o compiten) con los documentos oficiales de la Gaceta y mientras que, por un lado, la carta de J. J. Milanés narra la anécdota de dos escrituras enfrentadas (la del poeta, la del impresor-editor), el tono sencillo, breve y hasta costumbrista que imagina para la literatura cubana se asemeja, por el otro, a la "amena literatura" que ofrecían los periódicos de la época.

A pesar de sus divergencias, pues, hay un fondo común en estas lecturas. La presencia del formato periódico se deja leer incluso por su negatividad. Y es que, simultáneamente a aquella apertura textual de los años 1990, un desplazamiento mayor se estaba produciendo. Como ocurre con la taxonomía descriptiva de la lengua, que capta sus modificaciones una vez que estas cristalizan entre los hablantes, así suele ocurrir también con los cambios de paradigmas críticos. Y sería recién durante la primera década del nuevo milenio que el paradigma de la historia del libro e historia de la lectura se impondría definitivamente en el campo de los estudios decimonónicos. La imagen es la del movimiento tectónico, con ese grado de suculencia e irreversibilidad, al mismo tiempo que de efecto de larga duración.

En su recordada participación en la American Antiquarian Society -que pautaría el tránsito metodológico de la historia del libro a la de la lectura-, Roger Chartier, siguiendo las advertencias de Donald F. McKenzie, había postulado la necesidad de atender a las "huellas" dejadas por los textos (las formas de lo impreso), los dispositivos tipográficos y las variables del soporte textual a fin de volver menos abstracto el fenómeno de la lectura y, por ende, la propia historia del libro (obstinadamente cuantitativa).

$\mathrm{Al}$ mismo tiempo, y en parte como corolario de sus postulados McKenzianos, Chartier llamó la atención sobre un fenómeno que ya había sido examinado en varias zonas de su monumental Histoire de l'Edition Française: la hegemonía en el siglo XIX del periódico en la economía editorial. Luego de 1830, observaba Chartier, la edición "plagia del periódico la fórmula del libro publicado en fascículos y las entregas ampliamente ilustradas, vendidas a poco precio y lanzadas con gran despliegue de publicidad" $(32)^{6}$. La Histoire de

5 En un tan riguroso como virulento repaso de la obra de David Viñas (precisamente en el primer volumen publicado por la Historia crítica, dirigida por Noé Jitrik, La irrupción de la crítica), Julio Schvartzman apuntaba sobre su modelo: "La vocación de totalidad se resume en la palabra política, que queda, en aquel título fundante [Literatura argentina y realidad política], adosada a la realidad, frente a lo otro: la literatura" (148).

6 La conferencia dictada por Chartier y titulada "Frenchness in the History of the Book: from the History of Publishing to the History of Reading", fue recogida luego como primer capítulo de Libros, lecturas y lectores en la Edad Moderna (Madrid, Alianza Editorial, 1993), de donde extraigo la cita. 
l'Edition Française venía a refrendar lo que todas las historias de la prensa habían destacado: el siglo XIX es el siglo del periódico. De modo que a las razones materialistas de la lectura se sumaba, para el campo específico de los estudios decimonónicos, una constatación que la propia historia de la edición (francesa) venía a confirmar: el predominio del formato periódico en el comercio letrado a lo largo del siglo. La edición, la literatura, la lectura cobrarían mayor relieve, contornos más precisos, incorporando ese presupuesto a los métodos del análisis crítico.

Ahora bien, en la tradición de las críticas literarias latinoamericana y argentina hubo dos trabajos que, a su modo, sentaron las bases de lo que serían, varios lustros después, las principales inflexiones de aquella lenta, aunque perentoria, incorporación. Me refiero a El discurso criollista en la formación de la Argentina moderna (1988), de Adolfo Prieto y a Desencuentros de la modernidad en América Latina (1989), de Julio Ramos.

Ambos libros proveyeron una serie de reflexiones rigurosas que, todavía hoy, ejercen un influjo potente. Adolfo Prieto, preocupado por los alcances del surgimiento de un nuevo tipo de lector popular, que había hallado en la prensa "la nivelación de los códigos expresivos con que concurrían los distintos segmentos de la articulación social" (14), conjetura allí acerca de las funciones que cumplieron los impresos periódicos en esa cadena de diversificación lectora y analiza, minuciosamente, las fricciones, préstamos y cruces que se produjeron entre la cultura letrada tradicional y la expansión de la cultura popular. En la lectura de Prieto la presencia de folletos, periódicos, folletines, cancioneros y ediciones populares contrarresta las tradicionales visiones historiográficas que colocan al libro, como soporte privilegiado, en el centro.

Por su parte, Julio Ramos, siguiendo la escritura cronística de José Martí, entre otros modernistas, revisa con inteligencia el mito de la autonomización, señalando, como vimos, las limitaciones del sujeto letrado ramiano. La omnipresente figura del letrado, justificable en determinados niveles, impedía ver el rol dinamizador que, en Latinoamérica, producto del desfase institucional e industrial, tuvo como complemento el impreso periódico. La "fragmentación de la República de las letras" -tal el título de uno de los capítulos fundamentales del libro- se produce a partir de la proliferación de la prensa periódica finisecular, con la paradoja de que fue esa misma fragmentación la que otorgó un nuevo estatus al escritor. Es decir, el proceso es captado en términos ambivalentes, paradojales. De ahí el acierto de la fórmula de Ramos: "en, y contra, el periódico". En el prosaico espacio de las páginas periódicas, los escritores hallarían sin embargo los intersticios para enunciar su especificidad literaria.

La historia del libro, al igual que la historia de la prensa y de la imprenta, ha tenido desde luego su expresión local. En Argentina, por ejemplo, para hablar de un caso conocido, los legendarios trabajos de Rafael Alberto Arrieta (La ciudad y los libros, 1955) y Domingo Buonocore (Libreros, editores e impresores de Buenos Aires, 1974) fueron rigurosamente actualizados por Alejandro Parada, cuyos 
trabajos de investigación sobre libros, lecturas y bibliotecas en el temprano siglo XIX resultan hoy fundamentales ${ }^{7}$.

Pero el énfasis de los últimos años en la materialidad textual y en el universo de la lectura supuso, para el caso específico del siglo XIX, la reposición del impreso periódico -y sus aledaños: almanaques, folletos, hojas sueltas, álbumes- como elemento central del análisis crítico. No ya como "fuente" o apoyo empírico de las investigaciones, según apuntaba Carlos Ossandón (1998), sino como objeto con su propio espesor tipográfico y discursivo, que entabla relaciones con otros campos y discursos de la vida social. En este sentido, el viraje metodológico ha resultado estimulante ${ }^{8}$. En los últimos años, desde un paradigma multidisciplinar, la nueva escuela francesa de estudios sobre la prensa, cuyos resultados pueden consultarse en el monumental La civilisation du journal (2011), ha insistido aun en la necesidad de un abordaje cultural del objeto, al considerar al periódico la primera manifestación moderna de la cultura mediática?

Una serie de trabajos importantes, sin olvidar las lecciones de Ramos y Prieto, acompañaron esa constatación. La dorada garra de la lectura, de Susana Zanetti, fue tal vez una de las primeras aproximaciones globales al tema de los lectores y de la lectura en América Latina; el libro de Juan Poblete, Literatura chilena del siglo XIX: entre públicos lectores y figuras autoriales, aparecido un año después, resultó clave no solo para la historiografía tradicional chilena sino para pensar problemas comunes de las literaturas del período; El tiempo vacío de la ficción, de Alejandra Laera, demostró los alcances críticos alrededor de la materialidad de los impresos al leer la producción de Eduardo Gutiérrez y de Eugenio Cambaceres en estrecha correlación con la prensa; la maravillosa mirada atenta a los problemas de edición, redacción, lectura y autoría que realizó Paulette Silva Beauregard en Las tramas de los lectores. Estrategias de la modernización cultural en Venezuela, o los detallados trabajos de Claudia Roman sobre prensa satírica ilustrada en el Río de la Plata, y de Sandra Szir sobre cultura de la imagen, las indagaciones de Eduardo Romano y de Geraldine Rogers sobre popularización de la lectura alrededor del magazine Caras y Caretas, y el más reciente Cuando lo nuevo conquistó América. Prensa, moda y literatura en el sigo XIX, de Víctor Goldgel, son ejemplos destacados de la atención que suscita el formato periódico en los estudios culturales y literarios decimonónicos.

7 Cabe citar algunos títulos: El mundo del libro y de la lectura en la época de Rivadavia (1998), De la biblioteca particular a la biblioteca pública: libros, lectores y pensamiento bibliotecario en los orígenes de la Biblioteca Pública de Buenos Aires (2002), El orden y la memoria en la Librería Duportail Hermanos: un catálogo porteño de 1829 (2005), Los libros en la época del Salón Literario (2008).

8 La Revista Iberoamericana publicó en 2006 un número monográfico dedicado al Cambio cultural y lectura de periódicos en el siglo XIX en América Latina en el que se subrayan algunas de los significados de ese viraje; https://doi.org/10.5195/reviberoamer.2006.55.

9 Según esta mirada, la prensa operó una trasmutación capital, capaz de modificar incluso la idea misma de literatura (Dominique Kalifa, Alain Vaillant, "Pour une histoire culturelle et littéraire de la presse française au XIXème. siècle”, Le Temps des médias, n. ํ2, 2004, pp. 197-214. 
El periódico permite, además, recuperar una de las líneas más productivas del legado ramiano, aquella que entreteje, a partir de un objeto común, una mirada transfronteriza -e, incluso, internacional- del desarrollo cultural latinoamericano. Pues, como constató Sarmiento cuando escribía en la prensa de Chile, el periódico cruza fronteras, desdibuja los límites geográficos y permite una aproximación empírica a la idea de una República mundial de las letras.

En la literatura argentina, el giro materialista ha fundamentado los ejercicios de revisión. La cristalizada cultura letrada de la década de 1880, que David Viñas y Noé Jitrik (sin olvidar a Ricardo Rojas) contribuyeron a definir como la de los gentlemen escritores, por ejemplo, ha merecido nuevas y renovadas indagaciones.

Algunos de esos enfoques, siguiendo los surcos abiertos por Prieto y Laera, aunque con diferentes tempos y perspectivas, también se dieron a conocer en las páginas de Anclajes. Las reflexiones de Sandra Contreras sobre Mansilla, escritor - para retomar una fórmula que, con una insistencia llamativa, la crítica ha utilizado con Sarmiento-, y las hipótesis que guían su lectura -Mansilla es un escritorperiodista-literato, o, mejor dicho: un literato devenido escritor por concurso de su práctica periodística, no reconocido por la seriedad letrada de los críticos del 80- incitan a leer en los márgenes del capital simbólico de los gentlemen letrados del 80 la modernidad literaria y, con ella, los caminos de una profesionalización que, como en el caso de Mansilla, se asume deliberadamente sobre sus $\operatorname{críticos}^{10}$.

El criollismo rioplatense del 80 también se enlaza con una forma de lo popular, los cancioneros nacionales y regionales, cuyas compilaciones y ediciones crecen desde entonces hasta avanzado el siglo XX y en los que Andrea Bocco, cuya colaboración en la revista es un ejemplo de la concisión panorámica, logra captar la ambivalencia de sus alcances nacionalistas (desde Linch hasta Viggiano, pasando obviamente por Carrizo): construyen una tradición que mira hacia el pasado (ideal) y en la que, sin preverlo ni quererlo, se hacen presentes las masas populares del yrigoyenismo y del peronismo ${ }^{11}$.

También la prensa -y sus secciones, en este caso el folletín- se vuelve objeto central en otros dos trabajos tempranos publicados en Anclajes. El de Fabio Espósito, dedicado a Sud-América, el diario de Carlos Pellegrini, donde se publican varias novelas nacionales, analiza los modos en que el discurso político permea y se apoya en otras secciones del periódico, menos previsibles, particularmente en su folletín, donde las novelas -Espósito se centra aquí en Fruto vedado, de Paul Groussac- vienen a narrar "literariamente" lo que el editorial político sostiene de manera explícita ${ }^{12}$.

10 “Lucio V. Mansilla, ¿literato?”. Anclajes, vol. XXIII, n. ${ }^{\circ}$, enero-abril 2019, pp. 1-17, https:// doi.org/10.19137/anclajes-2019-2311.

11 "Tensiones entre proyectos intelectuales, políticas estatales y emergencia de las masas en los cancioneros populares". Anclajes, vol. XIII, n. ${ }^{\circ}$ 13, diciembre 2009, pp. 27-40.

12 "Los folletines del diario Sud-América. Las novelas de los patricios en la prensa política de 1880". Anclajes, vol. IX, n. ${ }^{\circ}$ 9, diciembre de 2005, pp. 39-51. 
El trabajo de Carlos Hernán Sosa, por su parte, también se centra en el folletín y en la prensa, en este caso en La Prensa Argentina, de los hermanos Gutiérrez. Sosa se enfoca en el Juan Moreira de Eduardo Gutiérrez para ver, a partir de un cotejo con los archivos judiciales, los modos de adecuación folletinesca que le sirvieron al escritor para buscar mayor impacto entre sus lectores (particularmente notable son, como sabemos, los cambios que Gutiérrez ejerce sobre figuras históricas laterales como, por ejemplo, el Juez de Paz Manuel Marañón, sobre los que el texto de Sosa se detiene especialmente a partir de las fojas judiciales) ${ }^{13}$.

En ambos casos, además, se trató de adelantos de investigaciones de tesis por entonces en curso, integrados luego al acervo bibliográfico sobre los escritores (y lectores) del ochenta en sendos libros: el de Espósito, bajo el título La emergencia de la novela en Argentina. La prensa, los lectores y la ciudad (1880-1890), publicado en 2009 por Ediciones Al Margen; el de Sosa, recientemente aparecido, con el título La novela gauchesca de Eduardo Gutiérrez. Prensa, discurso judicial y folletín en la génesis de una literatura popular, publicado en 2020 por Ediciones Katatay.

Resulta oportuno concluir este recorrido contrastando estos trabajos con uno de los últimos aportes sobre impresos y lectura en el siglo XIX chileno. Como ocurría en la década de 1880 en Argentina -en particular, por el tráfico promovido por el telégrafo-, la agitación social del crimen se hacía noticia escandalosa también en Chile. El cruel asesinato de Sara Bell producido en 1896 por uno de los vencedores de la llamada revolución de 1891, Luis Matta Pérez, perteneciente a la élite política y judicial chilena, es la excusa de la que se aprovecha el historiador chileno Tomás Cornejo para adentrarse en el mundo de la representación (la evocación a Chartier aquí no es vana) de la sociedad santiaguina finisecular: periódicos, libros, folletos, hojas sueltas, poemas populares (Lira popular), óperas y novelas, literatura dramática y "de actualidad" confluyeron alrededor del fatídico suceso. Estamos evidentemente ante un fenómeno, el de los "crímenes célebres", formateado popularmente a través de la prensa. No obstante, lo más destacado en este caso, según muestra Cornejo, es el modo en que voces "ilegítimas" emergen para hacer oír sus cosmovisiones alternas, agentes de una pugna por el espacio público que trasciende el hecho policial. Dicho de otro modo: el episodio, como una especie de vórtice temático de la cultura impresa, permite auscultar los usos que los diferentes públicos lectores -en particular, los públicos plebeyos- hicieron de la noticia.

La investigación de Cornejo se conoció hace poco, en un libro editado entre El Colegio de México y El Centro de Investigaciones Diego Barros Arana de la Biblioteca Nacional chilena, con el título Ciudad de voces impresas. Por la metodología empleada -se trata de un enfoque multidisciplinar, que parte de

13 "Las bondades de un buen 'justo': el enmascaramiento oportuno del folletín. Sobre procesos judiciales y ficciones populares en la Argentina de fines del siglo XIX”. Anclajes, vol. IX, n. ${ }^{\circ} 9$, diciembre 2005, pp. 141-156. 
la historia cultural-, el libro puede considerarse una muestra elocuente de la correspondencia predominante en los últimos lustros entre materialidad y lectura, entre historia y literatura. (Y, también, un ejemplo de la transformación del legado ramiano). Correspondencia de la que fueron dando cuenta, como vimos, la mayoría de los trabajos publicados en Anclajes, cuyo equipo editorial, en términos generales, mantuvo siempre una mirada atenta y rigurosa ante los avances de la crítica y, en particular, de la crítica dedicada al siglo XIX.

\section{Referencias bibliográficas}

Adorno, Rolena. "La ciudad letrada y los discursos coloniales". Hispamérica vol. XVI, n. ${ }^{\circ} 48,1987$, pp. 3-24.

Batticuore, Graciela. La mujer romántica. Lectoras, autoras y escritores en la Argentina: 1830-1870. Buenos Aires, Edhasa, 2005.

Cornejo C., Tomás. Ciudad de voces impresas. Historia cultural de Santiago de Chile, 1880-1910. Santiago, El Colegio de México, Centro de Estudios Históricos; Biblioteca Nacional de Chile, Centro de Investigaciones Diego Barros Arana, 2019.

Del Águila, Alicia. Los velos y las pieles. Cuerpo, género y reordenamiento social en el Perú republicano (Lima, 1822-1872), Lima, Instituto de Estudios Peruanos, 2003.

Goldgel, Víctor. Cuando lo nuevo conquistó América. Prensa, moda y literatura en el siglo XIX, Buenos Aires, Siglo XXI, 2013.

Gramuglio, María Teresa. "La crítica de la literatura. Un desplazamiento". Punto de vista, n. ${ }^{\circ}$ 60, XXI, 1998, pp. 3-12.

Kalifa, Dominique, Philippe Régnier, Marie-Ève Therenty et Alain Vaillant. La civilisation du journal. Histoire culturelle et littéraire de la presse française au XIXe siècle. Paris, Nouveau Monde éditions, 2011.

Laera, Alejandra. El tiempo vacio de la ficción. Las novelas argentinas de Eduardo Gutiérrez y Eugenio Cambaceres. Buenos Aires, Fondo de Cultura Económica, 2004.

Masiello, Francine (comp.). La mujer y el espacio público. El periodismo femenino en la Argentina del siglo XIX. Buenos Aires, Feminaria, 1994.

Morańa, Mabel (ed.). Ángel Rama y los estudios latinoamericanos. Pittsburgh, Universidad de Pittsburgh, Serie Críticas, 1997.

Ossandón, Carlos. El crepúsculo de los sabios y la irrupción de los publicistas. Santiago, LOM Ediciones, 1998. 
Poblete, Juan. Dossier "Cambio cultural y lectura de periódicos en el siglo XIX en América Latina”. Revista Iberoamericana, vol. LXXII, núm. 214, 2006, https://doi.org/10.5195/reviberoamer.2006.55

Poblete, Juan. Literatura chilena del siglo XIX: entre públicos lectores y figuras autoriales. Santiago, Editorial Cuarto Propio, 2003.

Prieto, Adolfo. El discurso criollista en la formación de la argentina moderna, 1988. Buenos Aires, Siglo XXI, 2006.

Ramos, Julio. Desencuentros de la modernidad en América Latina. Literatura y politica en el siglo XIX. México, Fondo de Cultura Económica, 1989.

Rogers, Geraldine. Caras y Caretas: cultura, politica y espectáculo en los inicios del siglo XX argentino. La Plata, Editorial de la Universidad de La Plata (Edulp), 2008.

Roman, Claudia. La prensa satírica argentina del siglo XIX: palabras e imágenes. Tesis doctoral, Universidad de Buenos Aires, 2011 (mimeo). http://repositorio.filo.uba.ar/handle/filodigital/1613

Roman, Claudia. Prensa, politica y cultura visual. El Mosquito (Buenos Aires, 1863-1893). Buenos Aires, Ampersand, 2017.

Romano, Eduardo. Revolución en la lectura. El discurso periodístico de las primeras revistas ilustradas rioplatenses. Buenos Aires, Catálogos, 2007.

Root, Regina. The Latin American Fashion Reader. Oxford, Berg, 2005.

Schvartzman, Julio. "David Vińas: la crítica como epopeya", La irrupción de la critica, volumen dirigido por Susana Cella, en Historia critica de la literatura argentina, dirigida por Noé Jitrik. Buenos Aires, Emecé, 1999, pp. 147-180.

Silva Beauregard, Paulette. Las tramas de los lectores. Estrategias de la modernización cultural en Venezuela (siglo XIX). Caracas, Fundación para la Cultura Urbana, 2007.

Szir, Sandra. "Romanticismo y cultura de la imagen en los primeros periódicos ilustrados en Buenos Aires. El Museo Americano, 1835-1836". Estudios vol. 18, n. 36 , julio-diciembre, 2010, pp. 296-322.

Szir, Sandra (coord.). Ilustrar e imprimir. Una historia de la cultura gráfica en Buenos Aires, 1830-1930. Buenos Aires, Ampersand, 2017.

Zanetti, Susana. La dorada garra de la lectura. Lectoras y lectores de novela en América Latina. Rosario, Beatriz Viterbo, 2002. 